\title{
Acute symptomatic mesenteric venous thrombosis: treatment by catheter-directed thrombolysis with transjugular intrahepatic route
}

\author{
Mao Qiang Wang, Feng Yong Liu, Feng Duan, Zhi Jun Wang, Peng Song, \\ Qing Sheng Fan
}

Department of Interventional Radiology, Chinese PLA General Hospital, Beijing, China

\begin{abstract}
Objective: To assess the feasibility and effectiveness of transjugular intrahepatic route aspiration thrombectomy and catheter-directed thrombolytic therapy in patients with acute superior mesenteric venous thrombosis. Materials and methods: During a period of 8 years, 12 patients with acute thrombosis of the superior mesenteric vein (SMV) were treated by transjugular intrahepatic approach. The mean age was 41.2 years. After access to the portal system via the transjugular approach, the pigtail catheter fragmentation of the thrombus, local urokinase injection, and manual aspiration thrombectomy were used for treatment of the SMV thrombosis initially, followed by continuous thrombolytic therapy via an indwelling infusion catheter in the SMV, which was performed for 2 to 6 days $(4.2 \pm 1.8$ days $)$. The adequacy of anticoagulation was performed during treatment, throughout hospitalization, and after discharge. Results: Technical success was achieved in all 12 patients. Substantial clinical improvement was seen in these patients after the procedure. Minor complications at the jugular puncture site were observed in 4 patients, but the thrombolytic therapy was not interrupted. Contrast-enhanced computed tomography (CT) scan before discharge demonstrated nearly complete disappearance of SMV thrombosis in all patients. The 12 patients were discharged 5-10 days $(7.6 \pm 2.0)$ after admission. Mean duration of follow-up after hospital discharge was 37.7 months, and no recurrent episodes of SMV thrombosis developed during that time period. Conclusion: Catheter-directed thrombus aspiration, mechanical
\end{abstract}

Correspondence to: Mao Qiang Wang; email: wangmq@vip.sina.com fragmentation, and local thrombolytic infusion via the transjugular intrahepatic route is a safe and effective therapy for the management of patients with acute symptomatic SMV thrombosis.

Key words: Superior mesenteric veinThrombosis-Thrombolysis-Mechanical thrombectomy-Interventional radiology

Acute superior mesenteric vein (SMV) thrombosis is an uncommon and insidious disease that is potentially lethal because its presenting symptoms overlap with those of many other diseases, leading to significant delays in diagnosis and therapy. Among all mesenteric ischemic events, mesenteric venous thrombosis accounts for 5\%$15 \%[1,2]$. There are no uniform protocols for the effective treatment of SMV thrombosis.

Generally, if the patient is suspected to have bowel infarction, an immediate exploratory laparotomy is needed. In patients without evidences of bowel infarction or perforation, systemic anticoagulation with heparin and supportive care are initial treatments [3-6]. However, systemic anticoagulation is of limited value in patients with acute extensive thrombosis of the SMV. Acute SMV thrombosis is still associated with $25 \%$ of extrahepatic portal vein hypertension and $18 \%$ transmural bowel infarction despite systemic anticoagulation [2].

Recently, endovascular selective catheterization thrombolytic therapy has been performed with increasing success. Endovascular thrombolytic therapy can be administered directly via percutaneous transhepatic [7-9] or transjugular intrahepatic routes [10-13] or indirectly via superior mesenteric artery (SMA) infusion of thrombolytic agents [14-16]. The objective of the present 
study is to report the clinical outcome of 12 patients with acute symptomatic SMV thrombosis who were treated by catheter-directed thrombolysis with tranjugular intrahepatic route at our hospital.

\section{Materials and methods}

The study was approved by the Institutional Review Board at our hospital. The potential risks and benefits of the procedure were explained, and informed consent was obtained from each patient.

\section{Patients}

Between October 2000 and November 2008, using the transjugular intrahepatic route, we treated 12 patients $(4$ women, 8 men) with a mean age of 41.2 years (range 18-75 years) who had symptomatic SMV thrombosis. All 12 patients had experienced acute symptoms of less than 3 weeks (range, 2-16 days; average, 8.0 days).

The following information was collected for each patient: demographic data, presenting symptoms, date of symptom onset, hospitalization and diagnosis, potential causative factors for the thrombosis, therapy and response to therapy, duration of hospitalization, and results at last follow-up.
The presenting symptoms are listed in Table 1. The most common symptom was abdominal pain, which was present in all 12 patients. Seven of these patients presented with severe abdominal pain; 5 of these patients presented with vague $(n=1)$ or moderate $(n=4)$ abdominal pain that progressively worsened. Other presenting symptoms included abdominal distension $(n=6)$, anorexia $(n=9)$, nausea $(n=8)$, vomiting $(n=4)$, melena $(n=3)$, diarrhea $(n=1)$, and low-grade fever $(n=2)$. All patients were hemodynamically stable, and no clinical signs of peritonitis were noted at abdominal examination.

An identifiable etiologic factor was found in 10 of these patients (Table 1). Four patients underwent splenectomy because of liver cirrhosis with portal hypertension and gastroesophageal variceal bleeding. The interval between the onset of symptoms of the SMV thrombosis and splenectomy was $22,30,32$, and 40 days, respectively. The other potential causative factors included serum protein $\mathrm{S}$ deficiency $(n=2)$, protein C deficiency $(n=1)$, antiphospholipid antibody syndrome $(n=1)$, hyperhemoglobinemia $(n=1)$, and deep venous thrombosis $(n=1)$.

\section{Diagnostic evaluation}

Increased white cell counts $\left(12.5 \pm 2.5 \times 10^{3} / \mathrm{mm}^{3}\right.$; range, $12.5-17.5 \times 10^{3} / \mathrm{mm}^{3}$ ) was found in 4 patients at

Table 1. Summary of clinical data

\begin{tabular}{|c|c|c|c|c|c|c|}
\hline $\begin{array}{l}\text { Pt. } \\
\text { No. }\end{array}$ & $\begin{array}{l}\text { Age/ } \\
\text { sex } \\
\text { (years) }\end{array}$ & Symptoms & Etiologies & Indication for intervention & $\begin{array}{l}\text { Days from } \\
\text { symptoms } \\
\text { to admission }\end{array}$ & $\begin{array}{l}\text { Days from } \\
\text { symptoms to } \\
\text { intervention }\end{array}$ \\
\hline 1 & $18 / \mathrm{M}$ & $\begin{array}{l}\text { Severe midabdominal pain, } \\
\text { distension, nausea, anorexia }\end{array}$ & Serum protein $\mathrm{S}$ deficiency & $\begin{array}{l}\text { Persistent pain despite } \\
\text { anticoagulation }\end{array}$ & 6 & 8 \\
\hline 2 & $44 / \mathrm{M}$ & $\begin{array}{l}\text { Severe abdominal pain, } \\
\quad \text { anorexia, distension, nausea }\end{array}$ & $\begin{array}{l}\text { Post-splenectomy day } 22, \\
\quad \text { PLT } 420 \times 10^{3} / \mathrm{mm}^{3}\end{array}$ & $\begin{array}{l}\text { Continued pain, despite } \\
\text { anticoagulation }\end{array}$ & 7 & 10 \\
\hline 3 & $52 / \mathrm{F}$ & $\begin{array}{l}\text { Moderate abdominal pain, } \\
\text { nausea, vomiting, anorexia, } \\
\text { progressively worsened }\end{array}$ & $\begin{array}{l}\text { Post-splenectomy day } 30 \\
\text { PLT540 } \times 10^{3} / \mathrm{mm}^{3}\end{array}$ & $\begin{array}{l}\text { Progressive pain, despite } \\
\text { anticoagulation }\end{array}$ & 11 & 14 \\
\hline 4 & $62 / \mathrm{M}$ & $\begin{array}{l}\text { Severity of midabdominal pain, } \\
\text { distension, nausea, anorexia }\end{array}$ & Serum protein $\mathrm{S}$ deficiency & $\begin{array}{l}\text { Severity of symptoms despite } \\
\text { anticoagulation }\end{array}$ & 5 & 7 \\
\hline 5 & $75 / \mathrm{M}$ & $\begin{array}{l}\text { Vague midabdominal pain, } \\
\text { distension, anorexia } \\
\text { progressively worsened }\end{array}$ & Unknown & $\begin{array}{l}\text { Continued pain, despite } \\
\text { anticoagulation }\end{array}$ & 12 & 14 \\
\hline 6 & $36 / \mathrm{F}$ & $\begin{array}{l}\text { Moderate abdominal pain, } \\
\text { nausea, anorexia, } \\
\text { progressively worsened }\end{array}$ & $\begin{array}{l}\text { Post-splenectomy day } 32 \\
\quad \text { PLT380 } \times 10^{3} / \mathrm{mm}^{3}\end{array}$ & $\begin{array}{l}\text { Continued pain, despite } \\
\text { anticoagulation }\end{array}$ & 16 & 19 \\
\hline 7 & $32 / \mathrm{M}$ & $\begin{array}{l}\text { Severe colicky abdominal pain, } \\
\text { nausea, vomiting, anorexia }\end{array}$ & $\begin{array}{l}\text { Post-splenectomy day } 40 \\
\text { PLT300 } \times 10^{3} / \mathrm{mm}^{3}\end{array}$ & $\begin{array}{l}\text { Worsening pain, despite } \\
\text { anticoagulation }\end{array}$ & 6 & 8 \\
\hline 8 & $24 / \mathrm{F}$ & $\begin{array}{l}\text { Moderate abdominal pain, } \\
\text { vomiting, diarrhea } \\
\text { progressively worsened }\end{array}$ & Serum protein $\mathrm{C}$ deficiency & $\begin{array}{l}\text { Severity of symptoms despite } \\
\text { anticoagulation }\end{array}$ & 4 & 6 \\
\hline 9 & $28 / \mathrm{M}$ & $\begin{array}{l}\text { Moderate midabdominal pain, } \\
\text { progressively worsened, } \\
\text { anorexia, melena }\end{array}$ & Antiphospholipid syndrome & $\begin{array}{l}\text { Worsening pain, despite } \\
\text { anticoagulation }\end{array}$ & 10 & 13 \\
\hline 10 & $49 / \mathrm{F}$ & $\begin{array}{l}\text { Severe abdominal pain, disten- } \\
\text { sion, nausea, low-grade fever }\end{array}$ & $\begin{array}{l}\text { A history of DVT, } \\
4 \text { months previously }\end{array}$ & $\begin{array}{l}\text { Persistent pain, distension, } \\
\text { despite anticoagulation }\end{array}$ & 9 & 12 \\
\hline 11 & $43 / \mathrm{M}$ & $\begin{array}{l}\text { Severe midabdominal pain, } \\
\text { nausea, melena, low-grade } \\
\text { fever }\end{array}$ & $\begin{array}{l}\text { Hyperhemoglobinemia, } \\
\text { hemoglobin } 21.5 \mathrm{~g} / \mathrm{dL}\end{array}$ & $\begin{array}{l}\text { Continued pain, despite } \\
\text { anticoagulation }\end{array}$ & 4 & 6 \\
\hline 12 & $31 / \mathrm{M}$ & $\begin{array}{l}\text { Severe midabdominal, pain, } \\
\quad \text { vomiting, distension, anorexia }\end{array}$ & Unknown & $\begin{array}{l}\text { Continued acuity of symptoms, } \\
\text { despite anticoagulation }\end{array}$ & 6 & 8 \\
\hline
\end{tabular}

DVT deep venous thrombosis, $P L T$ platelet 
admission. Plasma D-dimer was detected by latexagglutination assay in all 12 patients on admission, and the D-dimer levels were $>500 \mu \mathrm{g} / \mathrm{L}$ (range, $80-480 \mu \mathrm{g} / \mathrm{L}$; cut-off value, $\geq 500 \mu \mathrm{g} / \mathrm{L}$ ) in 5 patients, with range of $550-1420 \mu \mathrm{g} / \mathrm{L}$. Normal values were detected for thrombin time, C-reactive protein, serum s-lactate, and amylase.

Ultrasonography (US) and computed tomography (CT) were performed in all 12 patients. All patients had SMV thrombosis, which was confirmed by the imaging study. Mild ascites was identified in 3 patients. Esophagogastro-duodenoscopy was normal in 10 patients, mild varices in 2 patients.

\section{Initial management}

All patients were treated initially with bowel rest and nasogastric suction, intravenous fluid administration, broad-spectrum prophylactic antibiotics (including ampicillin, gentamycin, and metronidazole), and intravenous heparin adjusted to maintain the activated partial thromboplastin time between 2.0 and 2.5 times control.

Systemic anticoagulation after the diagnosis of SMV thrombosis was assessed for 2 days in 7 patients, and for 3 days in 5 patients; however, the symptoms continued $(n=7)$ or worsened $(n=5)$. After discussion with the surgery and medicine departments, and given the lack of clinical and radiographic suspicion for bowel infarction, plus systemic anticoagulation was ineffective, these patients were referred to the interventional radiology department for catheter-directed thrombolysis to achieve rapid restoration of the SMV flow. Mean duration from onset of symptoms to catheter-directed thrombolytic therapy was 10.4 days (Table 1).

\section{Indications and contraindications to interventional procedure}

In our hospital, the catheter-directed thrombolysis was employed in patients with acute SMV thrombosis, which involved the main trunk of the SMV, with severe symptoms, and/or persistent symptoms or worsening the abdominal pain despite anticoagulation.

The exclusion criteria of the tranjugular intrahepatic route included patients with evidences of bowel infarction or perforation, unfavorable anatomy (such as complete thrombosed portal vein, or portal venous cavernous transformation, and marked atrophy of the liver), and patient with high risk for bleeding.

Endovascular techniques. Before the transjugular approach was attempted, the portal system was studied with indirect portography obtained during the venous phase following iodinated contrast medium injections in the SMA and the splenic artery.
The transjugular approach was carried out according to the technique previously described $[10,11]$ by using US and fluoroscopic guidance of the portal vein puncture. Following infiltration of local anesthesia, a RoschUchida set (Cook, Bloomington, IN, USA) was used to gain access to the portal vein branch. Once the catheter was placed inside a portal branch, the thrombus of the SMV could be traversed with the aid of a 4-Fr Cobra catheter (Cordis, the Netherlands) and a 0.035-inch hydrophilic guidewire (Terumo, Japan). After reaching distal branches of the SMV, the Cobra catheter was exchanged for an $8 \mathrm{~mm}$ diameter angioplasty balloon catheter (Boston Scientific, MA, USA), to open up a channel, and then a 10-Fr Rosch-Uchida sheath (Cook) was put into the portal trunk. A bolus of $3000 \mathrm{IU}$ of heparin was injected via a peripheral venous catheter.

Through the $10-\mathrm{Fr}$ sheath, an angled $8-\mathrm{Fr}$ guiding catheter (Cordis) was used to aspirate as much of the thrombus as possible from the SMV with a Luer-Lok 60$\mathrm{mL}$ syringe. The aspiration procedure was performed from distal to proximal clots in 8-12 cycles $(10 \pm 2)$. Simultaneously, a 5-Fr pigtail catheter (Cordis) was used to fragment the thrombus with "spinning technique" [17] and an injection of urokinase (Tianjin Biochemical Pharmaceutical Co., Ltd, China) 200,000-300,000 IU using a hand-pulse spray technique.

Following the mechanical aspiration procedure, a 4-Fr multiple side-hole catheter (Angiodynamics, Queensbury, NY, USA) was placed with the tip in the SMV, and then continuous thrombolytic therapy was started with urokinase $50,000 \mathrm{IU} / \mathrm{h}$. Heparin infusion was given simultaneously via a peripheral venous catheter, at a dose of $1000 \mathrm{IU} / \mathrm{h}$. The adequacy of anticoagulation was adjusted to maintain the activated partial thromboplastin time between 2.0 and 2.5 times the control, during treatment and throughout hospitalization. During the prolonged infusion of thrombolytics, patients had the SMV venographic follow-up via the infusion catheter every $24 \mathrm{~h}$. Color Doppler ultrasound scan (CDUS) assessment of PV and SMV patency was performed at 24, 48, and $72 \mathrm{~h}, 1$ week following the procedure, and at discharge. Follow-up contrastenhanced CT was carried out in each patient before the infusion catheter removal.

Termination of the infusion of thrombolytics was based on clinical improvement and radiographic findings. The catheter infusion of thrombolytics was discontinued after the patients' symptoms (i.e., abdominal pain, anorexia, distension, and nausea) had improved sufficiently that they were able to begin oral intake, and the repeated venography demonstrated restoration of blood flow in the SMV, and CT follow-up confirmed complete or nearly complete lysis of the SMV thrombosis. The patients were then placed on chronic anticoagulation with warfarin adjusted to maintain an International Normalized Ratio of 2-3 after discharge. 

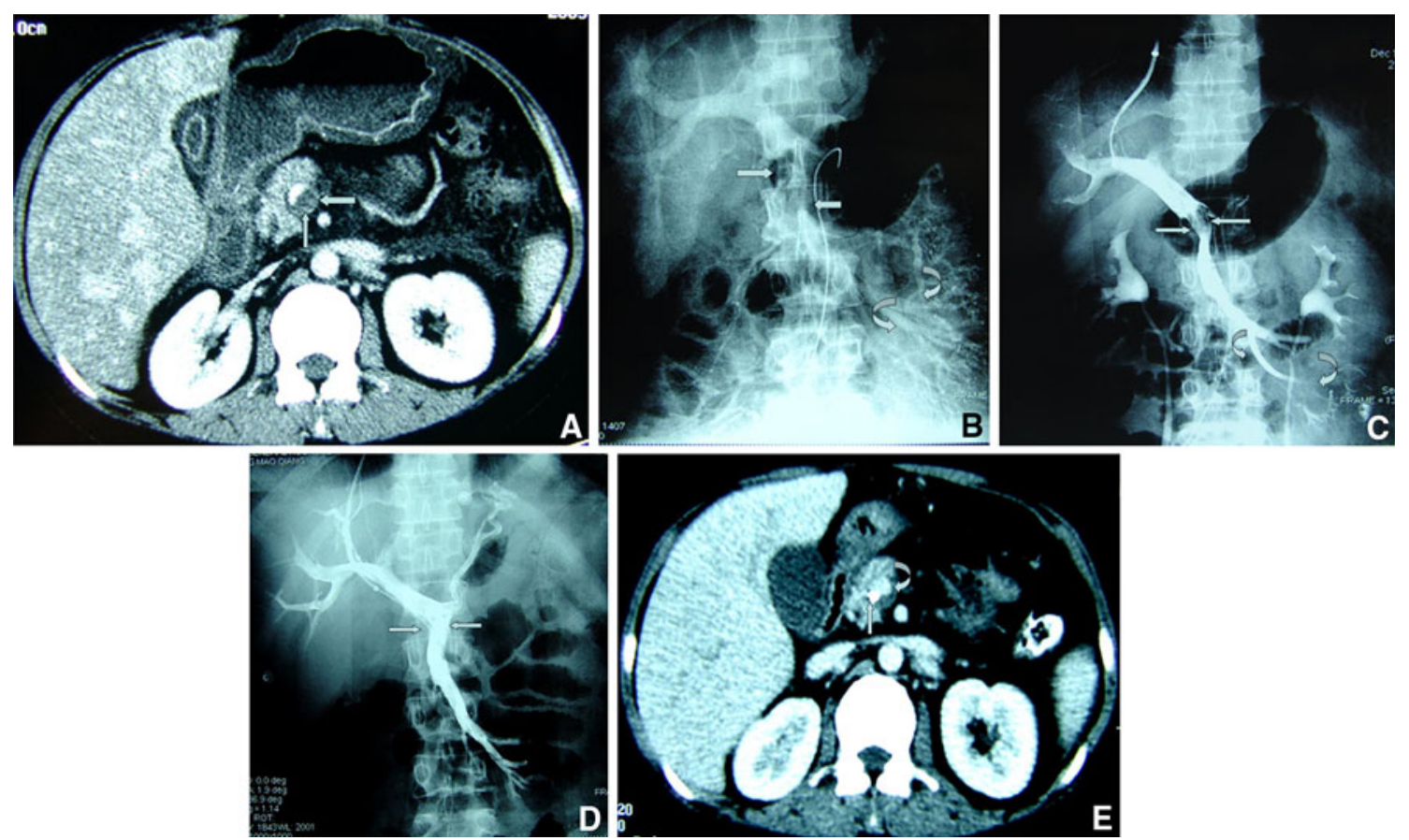

Fig. 1. A 24-year-old woman with moderate peri-umbilical abdominal pain, vomiting, and diarrhea for 4 days. A Selected axial image from admission contrast-enhanced CT shows massive thrombus within the SMV (straight arrows). B Pretreatment digital subtraction SMA angiogram with delayed (venous) phase shows no visualization of the trunk of the SMV (straight arrows), and remarkable pooling of contrast medium in the branches of the SMV (curved arrows). C Pretreatment direct venography via transjugular approach access

Follow-up CDUS was performed at discharge, every 2-3 months in the first year, and every 4-6 months in the second year. Follow-up contrast-enhanced CT was carried out at discharge, at every 3 months for 1 year, and at 6-12 months thereafter.

Technical success was defined as successful catheterization of the SMV, removal of the majority of clots, and restoration of flow in the SMV. Clinical success was defined as relief of symptoms and bowel resection was not required after the procedure.

\section{Results}

\section{Technical success}

Technical success was achieved in all 12 patients (Fig. 1). Mean procedural time was $75 \pm 15$ min (range 50-95). Using pigtail catheter fragmentation, local urokinase injection, and manual aspiration thrombectomy of the SMV thrombosis resulted in restoration of blood flow in the main SMV, which was documented on immediate follow-up direct SMV venography.

After the mechanical thrombolysis, continuous thrombolytic therapy via the indwelling catheter in the to portal vein shows massive thrombosis of the proximal SMV (straight arrows) and dilated jejunal veins (curved arrows). D Follow-up direct SMV venography via the infusion catheter, obtained 2 days after the SMV urokinase infusion, shows the widely patent SMV (straight arrows). E. CT image at the same level as in A, obtained 2 days after the SMV infusion of thrombolytics, shows the patent SMV with only minimal residual wall thrombus (curved arrow). Note the infusion catheter within the SMV (straight arrow).

SMV was performed for 2-6 days (4.2 \pm 1.8 days). Mean total dose of urokinase infusion was 5.0 million IU (range 2.6-7.2). Duration of the SMV urokinase infusion is listed in Table 2.

On completion of the SMV urokinase infusion, significantly improved filling of the SMV was seen in all 12 patients (Figs. 2, 3), which was confirmed by repeated venography via the infusion catheter. Contrast-enhanced CT images obtained before discharge demonstrated nearly complete lysis of SMV thrombosis in all patients. In addition, CT images showed improvement in edema of the intestine and mesentery in all patients (Fig. 4). Mild ascites, detected in 3 patients before the thrombolysis procedure, disappeared at discharge.

\section{Complications}

During urokinase infusion via the indwelling catheter in the SMV, minor complications at the internal jugular vein puncture site were observed in four patients: a small hematoma was observed in three patients, and a small amount of oozing of bloody fluid was observed in one patient. We simply applied light compression with sterile gauzes on the puncture site without interruption of the 
Table 2. Patient with SMV infusion of urokinase and clinical outcome

\begin{tabular}{|c|c|c|c|c|c|c|c|}
\hline $\begin{array}{l}\text { Pt. } \\
\text { No. }\end{array}$ & $\begin{array}{l}\text { Total } \\
\text { UK } \\
\text { dose }^{a}\end{array}$ & $\begin{array}{l}\text { Duration } \\
\text { of UK } \\
\text { infusion (days) }\end{array}$ & Complication & $\begin{array}{l}\text { Outcome of } \\
\text { CT follow-up }\end{array}$ & $\begin{array}{l}\text { Length of } \\
\text { hospital stay } \\
\text { (days) }\end{array}$ & $\begin{array}{l}\text { Length of } \\
\text { follow-up } \\
\text { (months) }\end{array}$ & Follow-up results \\
\hline 1 & 3.6 & 3 & None & Complete & 7 & 28 & No recurrence \\
\hline 2 & 4.8 & 4 & None & Complete & 8 & 12 & No recurrence \\
\hline 3 & 6.0 & 5 & None & Complete nearly & 9 & 66 & No recurrence \\
\hline 4 & 4.8 & 4 & None & Complete & 7 & 26 & No recurrence \\
\hline 5 & 6.0 & 5 & $\begin{array}{l}\text { A small hematoma at } \\
\text { the IJV puncture site }\end{array}$ & Complete & 9 & 38 & No recurrence \\
\hline 6 & 7.2 & 6 & $\begin{array}{l}\text { A little oozing of bloody } \\
\text { fluid at the IJV puncture site }\end{array}$ & Complete nearly & 10 & 62 & No recurrence \\
\hline 7 & 4.8 & 4 & None & Complete nearly & 7 & 46 & No recurrence \\
\hline 8 & 2.6 & 2 & None & Complete & 5 & 72 & No recurrence \\
\hline 9 & 6.0 & 5 & $\begin{array}{l}\text { A small hematoma at the } \\
\text { IJV puncture site }\end{array}$ & Complete nearly & 9 & 18 & No recurrence \\
\hline 10 & 4.8 & 4 & None & Complete nearly & 8 & 34 & No recurrence \\
\hline 11 & 6.0 & 5 & $\begin{array}{l}\text { A small hematoma at the } \\
\text { puncture site }\end{array}$ & Complete & 7 & 20 & No recurrence \\
\hline 12 & 3.8 & 3 & None & Complete & 5 & 30 & No recurrence \\
\hline
\end{tabular}

$U K$ urokinase, $I J V$ internal jugular vein

${ }^{a}$ Million IU

SMV infusion therapy. There were no cases of systemic bleeding or arterial puncture site bleeding.

\section{Clinical improvement}

Sufficient clinical improvement, characterized by progressive decrease in abdominal pain, nausea, and distension, was seen in all 12 patients after 12-24 h of the mechanical thrombolysis procedure. Clinical improvement continued during the thrombolytic therapy via the indwelling infusion catheter in the SMV. No patient required bowel resection after the procedure. The 12 patients were discharged 5-10 days $(7.6 \pm 2.0)$ after admission.

\section{Follow-up}

Mean duration of follow-up after hospital discharge was 37.7 months (range $12-72$ months). All 12 patients are alive at writing, and no recurrent episodes of the SMV thrombosis developed during the follow-up period. Chronic anticoagulation with oral warfarin was initiated in all patients at least 6 months (range 6-12 months) after hospital discharge. During the 12-72 months of follow-up, CDUS and contrast-enhanced CT confirmed the patency of the SMV.

Long-term oral aspirin was given at a dose of $100 \mathrm{mg} / \mathrm{day}$ to 4 patients who had splenectomy. Lifelong oral warfarin was suggested to the patients with deficiencies of serum protein $\mathrm{S}$ and protein $\mathrm{C}$, and antiphospholipid antibody syndrome.

\section{Discussion}

The exact mechanism and natural history of SMV thrombosis remain unclear. An identifiable etiology may be found in approximately $75 \%$ of patients, with as many as $56 \%$ of patients having identifiable coagulopathy [1, 2]. Most commonly, thrombosis of the SMV is a manifestation of a hypercoagulable state resulting from or exacerbated by an event such as pancreatitis or abdominal surgery. Thrombophilic conditions associated with the SMV thrombosis include deficiencies of antithrombin III, protein $\mathrm{C}$, and protein $\mathrm{S}$; factor V Leiden and prothrombin gene mutation; and the antiphospholipid antibody syndrome [3-5]. In our series, 10 (83.3\%) of 12 patients had potential causative factors, including splenectomy in 4 , deficiency of serum protein $\mathrm{S}$ in 2, and other causes in 4 patients.

In symptomatic SMV thrombosis patients, treatment depends on the presence or absence of clinical and imaging peritoneal signs $[5,6,18]$. An emergency laparotomy with resection of necrotic bowel is necessary in the former condition and anticoagulant and/or thrombolytic therapy in the latter condition. In patients without evidence of bowel infarction or perforation, systemic anticoagulation with heparin and supportive care comprises the initial treatment $[1,2]$. In our 12 patients, the diagnosis was made relatively early on presentation, yet the initial clinical and radiologic findings were impressive and suggestive of advanced disease. We chose the interventional procedure to treat these patients because systemic anticoagulation was ineffective.

Endovascular catheter-directed thrombolytic therapy has been proposed as a minimally invasive treatment option for patients with acute symptomatic SMV thrombosis [7-13]. With this approach, the SMV thrombosis can be managed by pharmacologic thrombolysis and/or mechanical thrombectomy. For pharmacologic thrombolysis, possible routes of treatment include indirect intra-arterial infusion of thrombolytic 


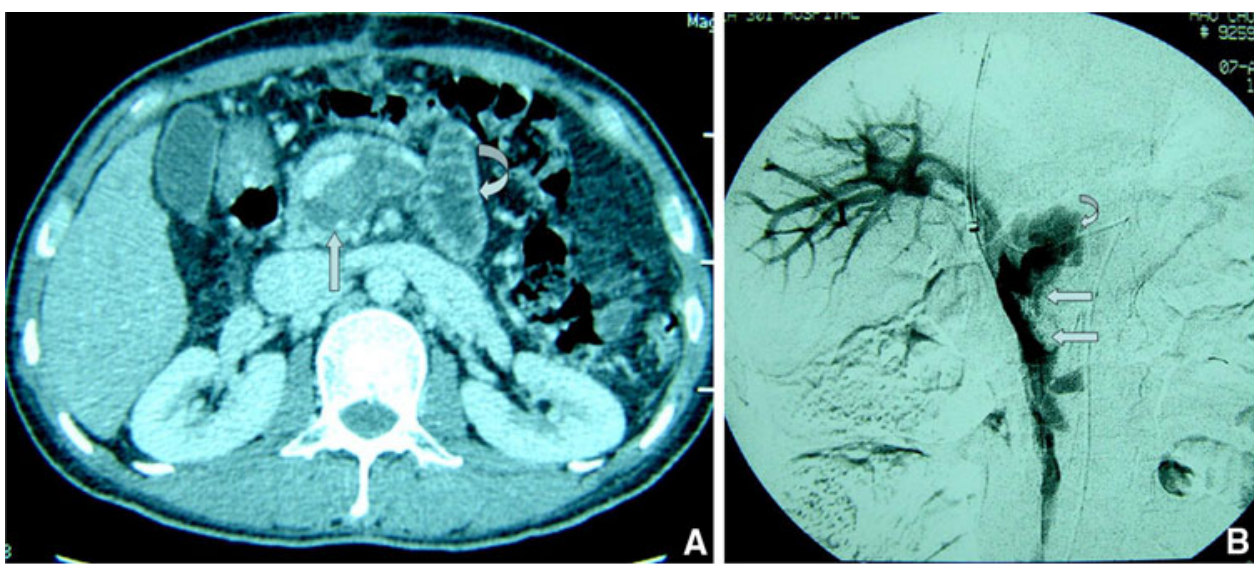

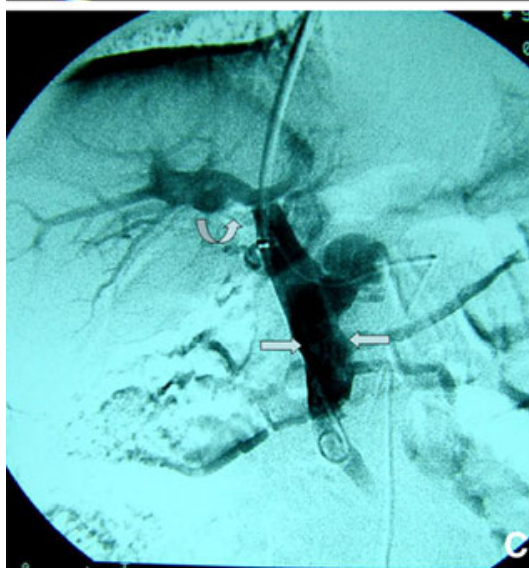

Fig. 2. A 44-year-old man with severe abdominal pain, distension, anorexia, and nausea for 7 days. He had undergone splenectomy 22 days previously. A Selected axial image from admission contrast-enhanced CT shows massive thrombus within the SMV (straight arrow). Note the edema of the small bowel (curved arrow). B Pre-treatment direct venography via transjugular approach access to portal vein shows massive thrombosis of the proximal SMV (straight arrows) extending into the main PV (arrows). Note the stump of the splenic vein

agents via the SMA [14-16] and direct access to the portal vein, by the transjugular [10-13] or transhepatic routes [7-9].

Indirect thrombolytic therapy via the SMA is less technically demanding and has been described for its potential benefits in infusing thrombolytic agents into small mesenteric venous branches $[15,16]$. However, this approach does not allow direct infusion into the thrombus, may result in lytic agents diverting through patent branches and collaterals, and possible prolongation of the total infusion time via the SMA [8-10], which may result in an increased risk of bleeding. In addition, the potential risk of thrombosis or embolization in the SMA and SMA branches is increased during prolonged catheterization.

Direct access to the portal vein by a transjugular or transhepatic route directly targets the SMV thrombosis, leading to fast removal of the thrombus and flow (curved arrow). C Immediate follow-up direct portal venography via a pigtail catheter, after the catheter fragmentation, local urokinase injection, and aspiration of the SMV thrombosis, shows good flow from the SMV (straight arrows) into the portal vein. Note the minimal residual wall thrombus in the main PV (curved arrow). D CT image at the same level as in A, obtained 4 days after the SMV urokinase infusion, shows widely patent SMV (curved arrow). Note the infusion catheter within the SMV (straight arrow).

improvement, and an improvement of symptoms [14, 15, 19]. Compared to indirect method, lysis by direct access to the SMV has advantages: it is more efficient, is less time-consuming, and decreases the dose of the thrombolytic agent, lowering the risk of related complications $[8,12,16,17]$. Catheter-directed thrombolysis in addition to anticoagulation should offer the advantage of improved lysis [5, 6, 20]. Equally important, re-establishment of antegrade flow, even incomplete, likely reduced the patients' risk of developing bowel infarction and allowed the additional time needed for infusion of thrombolytics and anticoagulation therapy.

Percutaneous transhepatic access is technically relatively easy and allows the maneuver of mechanical devices compared with transjugular intrahepatic access. Usually, this approach is suitable for the removal of larger thrombus within the trunk of the SMV. The drawbacks of the percutaneous transhepatic route in- 

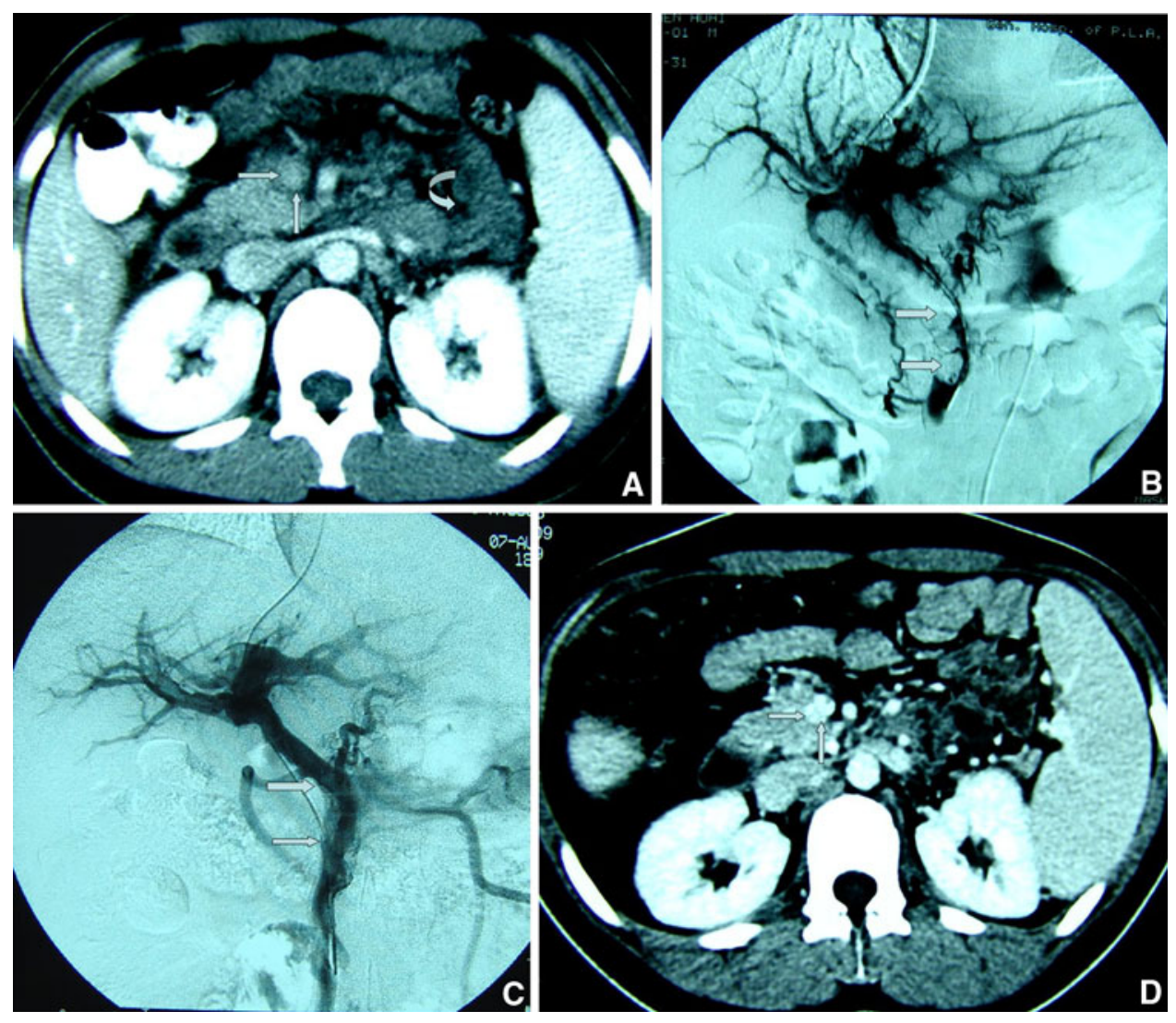

Fig. 3. A 43-year-old man with severe midabdominal pain, nausea, and fever for 4 days. A Selected axial image from admission contrast-enhanced CT shows thrombus (straight arrows) within the SMV. Note the dilated and thickened small bowel loop (curved arrow). B Pre-treatment direct venography via transjugular approach access to portal vein shows extensive thrombosis of the proximal SMV (straight arrows). C Follow-up direct portal venography via the infusion catheter, obtained 5 days after the SMV urokinase infusion, shows good flow from the SMV into the portal vein. Note the minimal residual wall thrombus in the main SMV (straight arrows). D CT image at the same level as in $\mathbf{A}$, obtained 5 days after the SMV urokinase infusion, shows patent SMV (straight arrows) with only minimal residual wall thrombus. clude the development of intraperitoneal or subcapsular hepatic hemorrhage [15, 17, 19,21]. This is likely to occur given that the transhepatic route requires traversing the hepatic capsule and is followed by thrombolysis and possibly systemic anticoagulation. In spite of portal vein access via a small peripheral branch and embolization of the tract during access removal, a subcapsular hemorrhage could not be avoided with this approach $[15,21$, 22]. In this situation, anticoagulation therapy had to be interrupted.

Our 12 patients treated with the transjugular intrahepatic route demonstrated the feasibility of this route to the management of this challenging illness. The transjugular approach access to the portal vein is generally performed with the creation of a transjugular intrahepatic portosystemic shunt; this approach is usually indicated for patients with cirrhosis with portal hypertension caused by portal vein thrombosis [11, 12]. Compared to the percutaneous transhepatic approach, the transjugular intrahepatic approach does not require traversing the hepatic capsule, and thus would eliminate the risk of subcapsular hemorrhage. Furthermore, the transjugular intrahepatic approach is safer in patients with ascites and anticoagulation. Our 12 patients were placed on adequate anticoagulation, which rendered them unsuitable for the percutaneous transhepatic approach. Although we did not observe significant bleeding complications in our patients with the transjugular intrahepatic approach, significant intra-abdominal bleeding is a potential serious complication [23, 24].

In patients with acute extensive SMV thrombosis, mechanical thrombectomy could initially be used to debulk the thrombus, and pharmacologic thrombolysis would probably still be necessary in most cases to treat residual thrombosis and to treat thrombus in the small and peripheral veins $[17,20]$. The combination of aspiration thrombus and local pharmacological thrombolysis via a direct access to the SMV is more effective in patients with extensive SMV thrombosis compared to direct mechanical thrombectomy alone $[8,10,20]$. In our 12 patients, aspiration the thrombus associated with an indwelling catheter infusion of thrombolytics into the SMV was effective, resulted in a rapid improvement in symptoms, recanalization of the SMV, and resolution of symptoms.

Combining thrombolytic infusion with anticoagulation would appear to increase the risk of bleeding and hemorrhage [22, 25, 26]. A study by Ouriel et al. [25] described the complication rates for patients with lowerextremity arterial or venous occlusions treated with local urokinase or rt-PA. Overall, 15\% required transfusion and $1.2 \%$ developed intracranial hemorrhage, which was fatal in 8 of 9 cases. In our series, no significant bleeding complications occurred. This may have resulted from the relatively low dose infusion of urokinase via the catheter in the SMV, no simultaneous peripheral venous infusion 

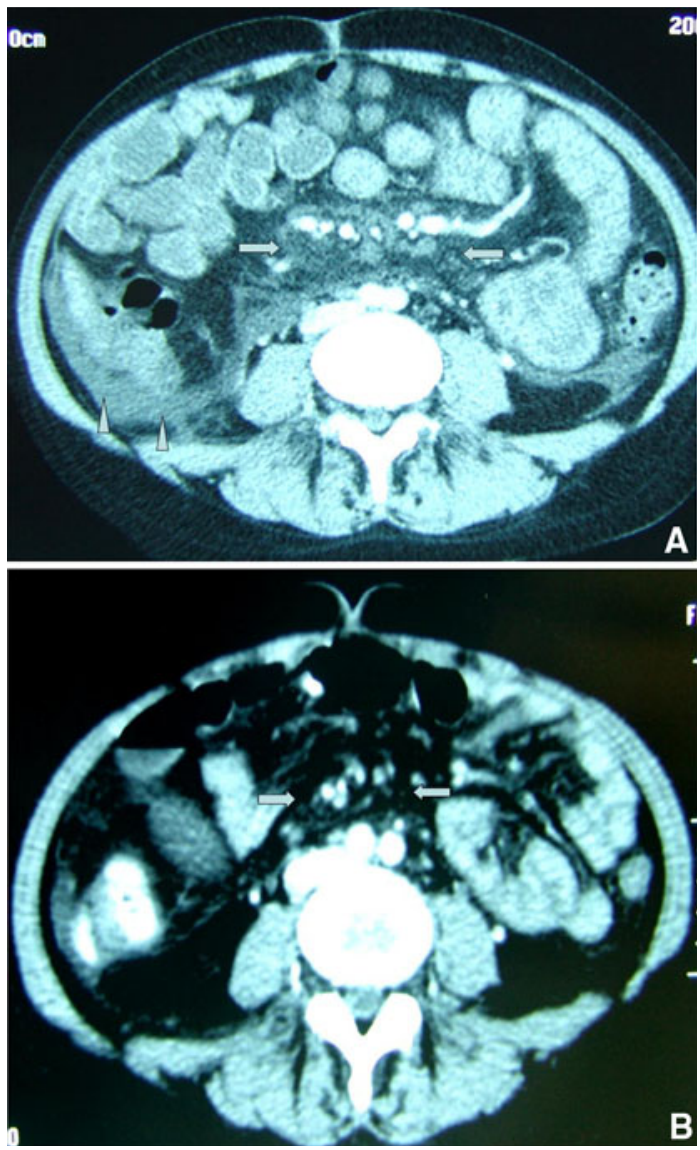

Fig. 4. A 31-year-old man with severe midabdominal pain, vomiting, distension, and anorexia for 6 days. A Selected axial image from admission contrast-enhanced CT shows diffuse edema of the mesentery (straight arrows), mild ascites (arrowheads), as well as multiple dilated and thickened small bowel loop. B Contrast-enhanced CT image taken at the same level shown in A obtained 3 days after the SMV urokinase infusion shows improvement in edema of the intestine and mesentery (straight arrows).

of urokinase, and careful monitoring of the coagulation status during treatment.

Endovascular catheter-directed thrombolytic therapy can offer a non-surgical alternative for the treatment of acute symptomatic SMV thrombosis. However, this can only be performed in a selected group of patients who do not present with transmural bowel infarction and peritonitis, or who are not at risk for bleeding, and who have persistent symptoms or worsening of symptoms despite anticoagulation [1, 2]. Minimally symptomatic or asymptomatic patients with the SMV thrombosis may best be treated with systemic anticoagulation only. Prompt surgical intervention should be undertaken if the patient's condition deteriorates or clinical signs of peritonitis develop during the interventional treatment $[2,6]$. The patients in our series had severe disease evidenced by radiographic findings and severe symptoms. Other factors included worsening symptoms despite anticoagulation.
The results obtained in our patient series can be considered satisfactory. All 12 patients showed a patent SMV, without recurrent episodes, during a mean follow-up of 37.7 months.

The limitations of this study include the lack of a control group, randomization, and uniformity of evaluation and treatment. Because of the small sample size, no statistically significant conclusions could be drawn regarding treatment with respect to dosages of thrombolytic agent or heparin, techniques, or underlying risk factors.

In summary, the combination of catheter fragmentation of thrombus, aspiration thrombectomy, and indwelling catheter infusion of thrombolytics via transjugular intrahepatic access to the portal system, is a safe and effective therapy for the management of patients with acute symptomatic SMV thrombosis. All 12 patients had subjective improvement in symptoms, had objective radiographic evidence of thrombolysis, and avoided bowel resection. Because of the small size of the study, the ability to generalize the results is limited.

Open Access. This article is distributed under the terms of the Creative Commons Attribution Noncommercial License which permits any noncommercial use, distribution, and reproduction in any medium, provided the original author(s) and source are credited.

\section{References}

1. Kumar S, Sarr MG, Kamath PS (2001) Mesenteric venous thrombosis. N Engl J Med 345:1683-1688

2. Brunaud L, Antunes L, Collinet-Adler S, et al. (2001) Acute mesenteric venous thrombosis: case for nonoperative management. J Vasc Surg 34:673-679

3. Amitrano L, Guardascione MA, Scaglione M, et al. (2007) Prognostic factors in noncirrhotic patients with splanchnic vein thromboses. Am J Gastroenterol 102:2464-2470

4. Acosta S, Alhadad A, Svensson P, Ekberg O (2008) Epidemiology, risk and prognostic factors in mesenteric venous thrombosis. $\mathrm{Br} \mathbf{J}$ Surg 95:1245-1251

5. Hedayati N, Riha GM, Kougias P, et al. (2008) Prognostic factors and treatment outcome in mesenteric vein thrombosis. Vasc Endovascular Surg 42:217-224

6. Cenedese A, Monneuse O, Gruner L, et al. (2009) Initial management of extensive mesenteric venous thrombosis: retrospective study of nine cases. World J Surg 33:2203-2208

7. Stambo GW, Grauer L (2005) Transhepatic portal venous powerpulse spray rheolytic thrombectomy for acute portal thrombosis after CT-guided pancreas biopsy. Am J Roentgenol 184(3 suppl): S118-S119

8. Kim HS, Patra A, Khan J, Arepally A, Streiff MB (2005) Transhepatic catheter-directed thrombectomy and thrombolysis of acute superior mesenteric venous thrombosis. J Vasc Interv Radiol 16:1685-1691

9. Hollingshead M, Burke CT, Mauro MA, et al. (2005) Transcatheter thrombolytic for acute mesenteric and portal vein thrombosis. J Vasc Interv Radiol 16:651-661

10. Sze DY, O’Sullivan GJ, Johnson DL, Dake MD (2000) Mesenteric and portal venous thrombosis treated by transjugular mechanical thrombolysis. Am J Roentgenol 175:732-734

11. Bilbao JI, Elorz M, Vivas I, et al. (2004) Transjugular intrahepatic portosystemic shunt (TIPS) in the treatment of venous symptomatic chronic portal thrombosis in non-cirrhotic patients. Cardiovasc Intervent Radiol 27:474-480

12. Ferro C, Rossi UG, Bovio G, Dahamane M, Centanaro M (2007) Transjugular intrahepatic portosystemic shunt, mechanical aspira- 
tion thrombectomy, and direct thrombolysis in the treatment of acute portal and superior mesenteric vein thrombosis. Cardiovasc Intervent Radiol 30:1070-1074

13. Nakayama S, Murashima N, Isobe Y (2008) Superior mesenteric venous thrombosis treated by direct aspiration thrombectomy. Hepatogastroenterology 55:367-370

14. Rosen MP, Sheiman R (2000) Transhepatic mechannical thrombectomy followed by infusion of TPA into the superior mesenteric artery to treat acute mesenteric vein thrombosis. J Vasc Interv Radiol 11:195-198

15. Hechelhammer L, Crook DW, Widmer U, Wildermuth S, Pfammatter T (2004) Thrombosis of a superior mesenteric vein aneurysm: transarterial thrombolysis and transhepatic aspiration thrombectomy. Cardiovase Intervent Radiol 27:551-555

16. Safieddine N, Mamazza J, Common A, Prabhudesai V (2007) Splenic and superior mesenteric artery thrombolytic infusion therapy for acute portal and mesenteric vein thrombosis. Can J Surg 50:68-69

17. Ozkan U, Oguzkurt L, Tercan F, Tokmak N (2006) Percutaneous transhepatic thrombolysis in the treatment of acute portal venous thrombosis. Diagn Interv Radiol 12:105-107

18. Bradbury MS, Kavanagh PV, Bechtold RE, et al. (2002) Mesenteric venous thrombosis: diagnosis and noninvasive imaging. Radiographics 22:527-541

19. Goldberg MF, Kim HS (2003) Treatment of acute superior mesenteric vein thrombosis with percutaneous techniques. Am J Roentgenol 181:1305-1307
20. Lopera JE, Correa G, Brazzini A, et al. (2002) Percutaneous transhepatic treatment of symptomatic mesenteric venous thrombosis. J Vasc Surg 36:1058-1061

21. Zhou W, Choi L, Lin PH, et al. (2007) Percutaneous transhepatic thrombectomy and pharmacologic thrombolysis of mesenteric venous thrombosis. Vascular 15:41-45

22. McManimon S, Ryu RK, Durham JD (1998) Mesenteric venous thrombosis. Tech Vasc Interv Radiol 1:209-215

23. Brountzos EN, Alexopoulou E, Koskinas I, et al. (2000) Intraperitoneal portal vein bleeding during transjugular intrahepatic portosystemic shunt: treatment with stent-graft placement. Am J Roentgenol 174:132-134

24. Owen AR, Stanley AJ, Vijayananthan A, Moss JG (2009) The transjugular intrahepatic portosystemic shunt (TIPS). Clin Radiol 64:664-674

25. Ouriel K, Gray B, Clair DG, Olin J (2000) Complications associated with the use of urokinase and recombinant tissue plasminogen activator for catheter-directed peripheral arterial and venous thrombolysis. J Vasc Interv Radiol 11:295-298

26. Schäfer C, Zundler J, Bode JC (2000) Thrombolytic therapy in patients with portal vein thrombosis: case report and review of the literature. Eur J Gastroenterol Hepatol 12:1141-1145 